\title{
Words are Silver, Mouse-Clicks are Gold? (or how to optimize the level of language formalization of young students in a Logo-based cubics world)
}

\author{
One should NOT aim at being possible to understand, \\ but at being IMPOSSIBLE to misunderstand.
}

Quintilian, circa $100 \mathrm{AD}$

\section{Evgenia SENDOVA}

Institute of Mathematics and Informatics, Bulgarian Academy of Sciences

bl.8Acad. G. Bonchex St.1113 Sofia, Bulgaria

e-mail: jsendova@mit.edu

Toni CHEHLAROVA

Faculty of Mathematics and Informatics, Plovdiv University

bl.8Acad. G. Bonchex St.1113 Sofia, Bulgaria

e-mail: tchehlarova@mail.bg

\section{Pavel BOYTCHEV}

Faculty of Mathematics and Informatics, Sofia University, Bulgaria

5, James Baurchier, 1126 Sofia, Bulgaria

e-mail: boytchev@fmi.uni-sofia.bg

Received: August 2007

\begin{abstract}
How do we teach children to express and communicate ideas in a formal and informal mode? What type of language do they need in a concrete context? How should they determine a proper level of formalization of their descriptions? In an attempt to explore these issues we carried out a pilot experiment in the frames of the DALEST European project whose goal was to create environment for stimulating the 3D geometry understanding of young students and to assist them in developing some fundamental mathematical skills including spatial visualization and articulating ideas. The pilot experiment was carried out with 5th graders from five Bulgarian schools by means of specially designed educational scenarios and the Cubix Editor (a Logo based application for manipulating unit-sized cubes). The children were given tasks to describe compositions of unit-sized cubes and to build such compositions by means of the Cubix Editor when given their descriptions by peers. The students experienced the whole process of generating a good description - becoming aware of the ambiguity, producing counterexamples, reducing the ambiguity, eliminating the redundancy.

The pilot experiment aimed at specifying the structure, scope and methods behind the stereometry activities envisaged for 5 th graders in the frames of the DALEST project.

The first impressions confirm our belief that the language is playing significant role in the learning experiences of the students, that the relationship between thoughts and words involves back and forth reshaping process. While constructing and describing cubical structures they articulated their own ideas, developed concepts collaboratively with others, moved between everyday and mathematical terms, between procedural and declarative style, exploring the boundaries of understanding.
\end{abstract}


Such interplay with the step-wise refinement of their descriptions of cubical structures would hopefully enhance students' skills for working with mathematical definitions, on one hand, and prepare them for writing, debugging and explaining programs, on the other.

Key words: language, formalization, definition, precision, virtual world, 3D visualization, mathematics, Logo, teaching and learning.

\section{The Role of a Language when Learning Math in a Computer Environment}

Learning to Express and Communicate Ideas - an Educational Challenge

Students find it difficult to express themselves. To express one's thoughts clearly and precisely involves significant cognitive processes that pass through different levels of formalization. Learning a language, to use John Austin celebrated phrase, is learning how to do things with words - not simply what to say, but how, where, to whom, and under what circumstances (Bruner, 1990).

It has been suggested (Truss, 1999; Khait, 2005) that mathematics is an essentially linguistic activity characterized by association of words with precise meanings. The classical use of definitions in mathematics is to introduce new concepts (Vinner, 1991). The information society has added a new aspect - a competent professional has to construct new definitions of various computer objects and understand definitions constructed by colleagues. Furthermore, mathematical literacy can be interpreted (Kent and Noss, 2002) as an ability to communicate ideas, based on an understanding of the ways in which the ideas can be expressed. Experts in mathematics and informatics education find that the most important component of the mathematical way of thinking for workers in ICT is the ability to express their ideas in a rigorous language, where each word and expression has an unambiguous meaning (Khait, 2003).

The work of the citizen of the information society could be seen as ongoing transition between formal (human-computer) an informal (human-human) communications. Thus the education should take care of enhancing the abilities of the students to translate their intuition to a formal language, to create definitions of new abstract objects, to write comprehensible descriptions of abstract and real structures and to understand those created by others.

The main problem we have been interested for years is how the young students "grasp the significance" of situations in a way that can help them master the lexicon that fits the situation. Or more concretely, how to develop the ability of students to articulate their ideas in an ICT enhanced environment. Since learning how to push the frontier of what we can express with words (Papert, 1980) has always been a very important and appealing educational goal.

\section{Looking Back}

In the early days of launching computers in Bulgarian education Logo was introduced as a part of an integrated subject for 5th and 6th graders - Language and Mathematics taught in the frames of a Bulgarian educational experiment (Nikolov and Sendova, 1991). The intention was to show the intersection of the language study with mathematical thinking in the context of informatics. Differences and similarities between the natural 
languages and formal languages (mathematics and Logo) have been discussed with the students. In addition to being a formal language, Logo was appreciated as an executable language, giving an immediate feedback of one's reasoning. The experimental textbooks included problems on translation from a natural language into an artificial language and vice versa, algorithmic descriptions of grammar rules, etc. A further step in that direction was the development of integrated textbooks in mathematics and informatics (Dicheva et al., 1997) in which the traditional mathematics definitions (e.g., about symmetry) were accompanied by Logo procedures.

An important component of the educational experiment involved development of software tools for mathematical explorations based on a linguistic structure (Sendov and Sendova, 1993). Thanks to appropriately designed Logo-based environments such as $\mathrm{Ge}$ omland (Sendov and Dicheva, 1988; Filimonov and Sendov, 1989) students were able to make their mathematics definitions workable and even to correct some definitions published in the math textbooks (Sendova, 1992).

\section{Developer's Perspective on Languages - a Glance BK}

Of course, programming languages are special type of tools for expresssing ideas, not only those of users, but also of developers. Most of the programming languages are settled into a rut. Changes occure very rarely and after a long period of redesign. The Logo language is quite different. It helps users to enrich the language with their own definitions, but it also inspires people to make their own dialects of Logo. It is hard to implement a programming language but the educational philosophy behind Logo is so appealing that many people got the courage to make their own versions. For the first 40 years of its existence Logo had more than 170 different implementations. Some of them are made by teams of professionals, others - by researchers and students at Universities, and yet a third part of Logos - by parents. The common feature of most Logo developers is that they did it for fun.

Five years ago The Logo Tree Project was launched (Boytchev, 2007). The goal of the project was to build a genealogical tree of all known new and old Logo implementations. This tree was expected to demonstrate the evolution, the diversity and the vitality of Logo as a programming language.

The project has three phases. The first phase, Data Collection, has started in September 2002 and is aiming at collecting some basic data about each Logo implementation name, versions, dates, platform, inspirators. The second phase, Data Analysis, is meant to get clusters of historically and evolutionary related Logos and to analyze the internal relationships among Logo implementations. The last phase is the Data Visualization focusing on the interactive visual representation of the Logo Tree.

\section{Clicking vs. Speaking}

There are still ongoing discussions of whether we need a programming language when using computers for educational purposes, and if so, which languages are the most appropriate ones. Even enthusiastic supporters of Logo as educational philosophy and culture claim that this language is only an indication of what might be offered in the future. But 
the very fact that it is indication is significant (Noss, 1993). Those who find programming languages to be a great obstacle for teachers advocate the direct manipulation tool kits: If the exploratory spirit in school could be achieved by tools with "ease-of-use features" why should we insist on working with languages? The answer is not to contrast the two approaches - the software designers should develop continuous media providing the whole range, from easy means for making sketches up to means enabling you to create the tools you need (Sendov and Sendova, 1995).

What the Level of Precision of Speech Should Be?

Among the multiple versions of the famous joke about the way different scientists (a philosopher, a physicist, a mathematician and a programmer) described a herd of cows, we particularly like the following - the philosopher stated: all the cows are black; his physicist friend corrected him: all the cows in that herd are black, the mathematician said: all the cows in that herd visible from here are black - and the programmer added: all the cows in that herd visible from here are black at least from their visible side.

Such a gradation of the precision of human speech reflects well certain inadequacy of the way we sometimes express ourselves influenced by our profession. If the goal of math educators is that students learn to formalize their thinking and to understand at least part of the mathematical language, the professional mathematicians are going to the other extremity - some seem to take greater pride in how few people could read their work, than in how many people had read their work. According to the poetic expression of Ó Dúill Logo's level of formalization is intermediate between mathematics and natural language - between Gödel and Goethe. Thus, for us, the Logo fans, it was natural to look for a way to make the students verbalize their thinking even when they are clicking! And further on - to develop their skills in choosing a reasonable level of formalization depending on the context.

\section{The Experiment with Cubical Constructions}

Our rational behind the experiment was that the mastery of mathematics definitions (language) can come from participation in formal language as an instrument for communication. For the purpose we designed the following scenario:

\section{The Scenario}

- Writing description of various cubical constructions by $2 \mathrm{D}$ representations.

- Building constructions of fixed number of cubes by means of a Logo application and describing them to a peer so that s/he could reproduce the construction.

- Joint explorations of descriptions produced by the students.

- Back and forth process of reshaping the descriptions. Discussion.

- Free style constructions.

- Identifying the right level of formal description. 
The Participants

The official participants were students from 5th grade attending five schools from Sofia and Plovdiv of slightly different nature - two mathematics schools with intensive study of mathematics and three others - with a traditional curriculum, with extracurricular activities in mathematics, and with high specialization in sports, respectively.

\section{The Construction Tool}

The main tool for creating the cubical constructions we used was Cubix Editor - a specially designed Elica-Logo application (Boytchev, 2007). It was developed in the frames of the DALEST project (http: / /www . ucy . ac . cy/dalest/) whose goal is to enhance middle school students' $3 \mathrm{D}$ geometry understanding and spatial visualization skills by working with dynamic visualization images (Boytchev et al., 2007). The theoretical background behind the design of the DALEST software has been considered in details in (Christou et al., 2007). Cubix Editor allows the construction of 3D unit-sized cube structures by clicking. The students can make a library of various constructions (Fig. 1). A very useful characteristic of the application is the rotation of the platform, which enables dynamic visualizations of the front, side and top view.

\section{Episode 1: A simple construction - multiple descriptions}

The first problem was to describe three versions of a construction (Fig. 2).

The idea was to check if the students would take into account the colors and relate the position of the construction to a board. The coordinate system has still not been introduced.

Which mathematical terms can we use? Are you going to grade us? May I explain it without writing? Are you going to check my spelling? - these were the typical questions asked. In order to predispose kids to write the way they believe was the most suitable for a peer to reconstruct the figure we told them the philosopher-vs.-programmer joke quoted above. Little we knew ....

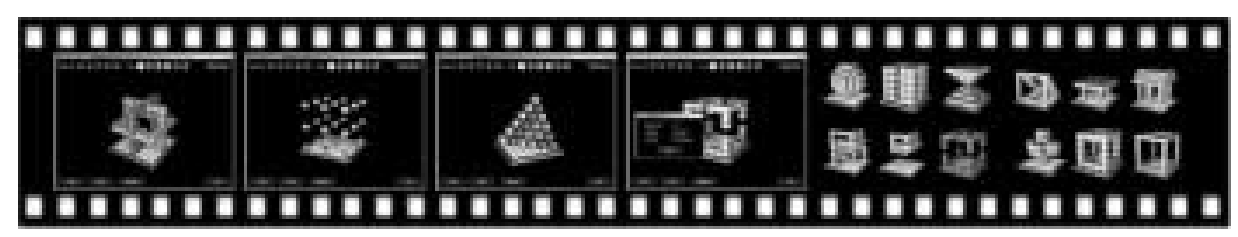

Fig. 1. Cubix Editor - some constructions of its library.

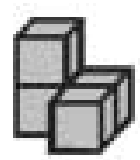

a

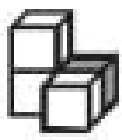

$b$

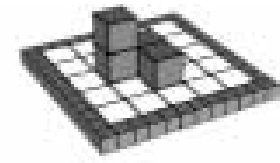

C

Fig. 2. Three versions of a 4-cube construction for students to describe. 
The first class from Sofia Math School had no experience with the Cubix Editor. It was interesting for us to see to what extent the students would be influenced by the "silent contract" of implementing the topics learned most recently - volume and surface of solids. (Students' names are fictitious since they were concerned with possible grammar and spelling mistakes.)

Damian: Fig. 2-a consists of 4 cubes of the same color. Its surface is 18.

Maria: Fig. 2-a consists of 4 cubes of the same color. 2 of them are joint in an upright rectangular cuboid, and the rest 2 form a flatwise rectangular cuboid. The two cuboids are joint so that the bottom cube of the upright cuboid is glued to the back cube of the flatwise one.

Lea: Fig. 2-a has 4 cubes with 18 sides all being grey. It consists of two cuboids the base of the first one is its smaller side, and that of the second-its bigger side.

Peter: Fig. 2-a consists of 4 cubes and its volume is $4 \mathrm{~cm}^{3}$. They form two cuboids - one of altitude $1 \mathrm{~cm}$, and the other of altitude $2 \mathrm{~cm}$.

Others included the board in their descriptions as a construction of smaller cubes:

Jenny: There are 44 cubes in a square form. There are 25 bigger cubes inside completing the square. There is a building on the whole square: two cubes one on top of the other and next to them glued aside - another such little "tower".

The most unexpected for us was their literal reflecting the joke we told them at the beginning so as to illustrate the different levels of speech precision:

Veronica: On Fig. 2-a we see 4 cubes - next to an upright cuboid formed by 2 cubes another 2-cube cuboid is flatwise. All cubes are grey from their visible side.

Denitsa: There are 4 cubes on Fig. 2-b. Under the first one there is another cube. There is a cube to the right of the second one and all its visible sides are dark. The visible sides of the rest of the cubes are white.

The students from Plovdiv who already had been working with the Cubix Editor used the board to locate the cubes similarly to a chess board:

Koya: The board is $5 \times 5$. I denote the columns $A, B, C, D, E$ and the rows $-1,2,3$, 4, 5. Then Fig. 2-a could be described as follows: a cube on C3. A cube on D3. On

D4 there is a cube and on top of it-another one.

Let us note that when describing Fig. 2-b Koya thought of adding the color as a third element of the information needed. This would be a smooth transition for Koya to learn about the classical way of presenting the position of each unit cube in the space by means of coordinate systems. For Fig. 2-a possible representations of the kind are:

- $(2 ; 1 ; 1) ;(2 ; 2 ; 1) ;(1 ; 2 ; 1) ;(1 ; 2 ; 2)$ - an imaginary relative coordinate system fitting the size of the construction $(2 \times 2 \times 2)$, or

- $(3 ; 2 ; 1) ;(3 ; 3 ; 1) ;(2 ; 3 ; 1) ;(2 ; 3 ; 2)$ - an absolute coordinate system associated with the board. For Fig. 2-b the color should be added as a fourth coordinate.

The richness of possible descriptions even with such a simple construction was a matter of hot discussions among the students. Some kids gave several descriptions of the same figure:

Neda (6th grade): There is an angle of 3 cubes. On top of the one which is not the corner, there is another cube, or I could say: 
There is a square on the board of 4 cubes. One of the cubes is lifted and put on a cube next to it.

We encouraged them to formulate their own criteria about what would be a "better description" - more understandable, more clear, shorter. Standard mathematics notation turned out to be helpful but it would often be mixed with everyday terms:

Maria: Take 4 cubes and label them $\boldsymbol{a}, \boldsymbol{b}, \boldsymbol{c}, \boldsymbol{d}$. Arrange them in the shape of a chair of your taste. They have 12 sides and 8 vertices. $\boldsymbol{a}$ is on top of $\boldsymbol{b}$, and $\boldsymbol{c}$ is next to d.

Vesko: The solid consists of 4 cubes, 3 of which form a right angle. One of the cubes is on top of one of the ending cubes.

Boyan: 3 cuboids are of size $(2 \boldsymbol{a} \times \boldsymbol{a} \times \boldsymbol{a})$. Every two cuboids have a common vertex.

Svetla: Put 2 cubes next to each other. Put a cube on top of the left and in front of the right one.

Although many of the students had used the terms left cube and right cube there was a student from the Plovdiv Athletic School (having worked with Cubix Editor) who immediately said: If I look from behind, the description will be different. By the way the problems of explaining the notion of "left" to someone who doesn't see what we see was discussed in (Feynman et al., 1971): If we tell a Martian that our heart is on the left side, he would ask: "Duhhh - the left side?" Now our problem is to describe to him which side the heart goes on without his ever seeing anything that we see, and without our ever sending any sample to him of what we mean by "right" - no standard right-handed object. Can we do it?

\section{Episode 2: Constructing and describing simple compositions}

The second task was to build constructions of fixed number of cubes ( 5 and 10) by means of Cubix Editor and to describe them to a peer so that s/he could reproduce the construction.

Even in the case of 5-cubes figures it was unexpected for the students to see that their descriptions were ambiguous.

Alija: 5 cubes are put on the board as follows: 2 sideward, starting from the last - one more forward, next to it one more, and starting from the last cube one more forward.

When constructing his composition after Alija's description (Fig. 3) Georgi showed how he would describe his own construction to eliminate the ambiguity:
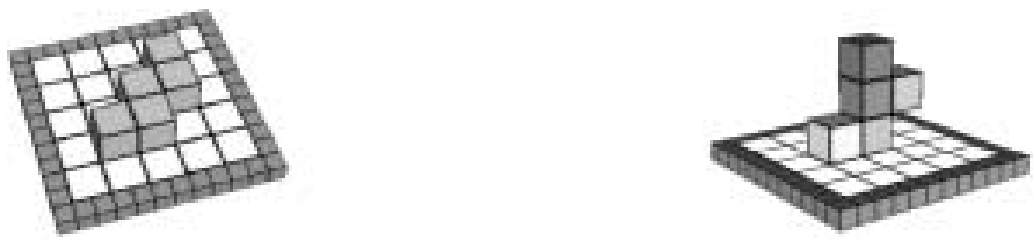

Fig. 3. Alija's original construction and Georgi's materialised description of it. 
Georgi: A pink cube is put on the $3 d$ row of the 2 nd column of a $5 \times 5$ board. Next to it on its right (again in the $3 d$ row) there is a green cube. On the top of it - a red cube, next to it in the air is glued a yellow one.

Most descriptions were in a declarative style - this was expected since the students will learn their first programming language, Logo, in 6th grade:

Emmy: 4 cubes are touching each other in such a way that if looked from above they form a square. On the top of one of the corners there is a cube.

Still there were a few in a procedural style:

Pavlina: On the $5 \times 5$ board put green cubes as follows: put 3 cubes on the second row on the middle 3 squares. Repeat the same on the $3 d$ and the 4th row. Put another cube on the top of the central cube of those already constructed.

Some students coined their own terms such as empty square - a square having its middle cubes removed. Still there were some rather fuzzy (although imaginative) descriptions, e.g., 10 cubes in the shape of T (sort of); "L" is formed of 4 cubes; a "plus" flatwise; a 3-hump snake, a gun lying down, stairs, castle, wall, tower.

The interaction of language and thought has been described by Vygotski (1934) by means of a dynamic model: Thought is not merely expressed in words; it comes into existence through them, this relationship between thoughts and words involving back and forth reshaping process.

\section{Episode 3: Back and forth between clicking and speaking}

Such a reshaping process becomes very natural when having an object to think with - a virtual manipulable construction. Making consecutive refinements of a description was in the core of the learning scenario for the next session. The students were expected:

- to start constructing after a description of a peer (chosen by the teacher);

- to demonstrate that the proposed description is not complete;

- to improve the description written on the board;

- to construct and describe their own figure.

The description of a construction given by one of the kids reads: 12 cubes are put in groups of 3 so that every 3 form a right angle. Each group touches the other one by a cube. They are colored. The description together with different solutions according to it is shown in Fig. 4. Note that the idea of coloring the separate groups in different colors was generated by the kids without this being explicitly stated in the description. Some students showed different solutions on a single board.
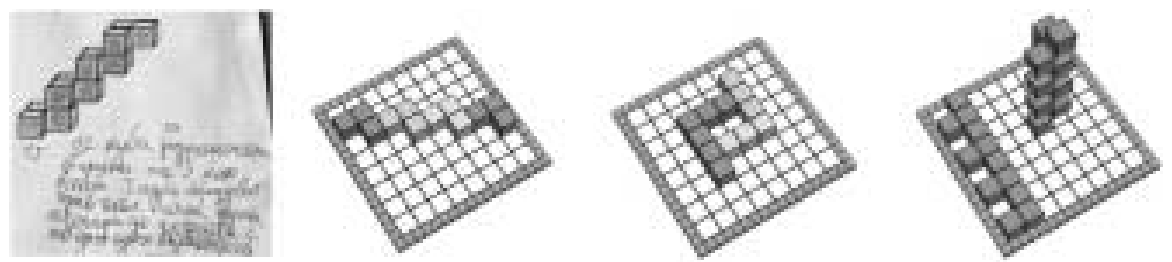

Fig. 4. Constructions based on a description of a classmate. 
When the students looked around and saw so many different constructions fitting the description they were eager to see the original. Then their reactions differed as well:

Ivan: I got it right, you didn't!

Iliana: I can construct another one fitting this description.

Boris: Here is how you can improve the description - three cubes are forming an angle. We put on top of one of the ending cubes again a 3-cube angle. And so on, until we have 4 angles.

Similar was the process of materializing the description of another student of the same class: There are 11 cubes. 4 are on a horizontal line, 2 are on a line perpendicular to it, and from these two cubes three new are rising. Out of the three cubes two are sticking out. The original and different solutions of the students are shown in Fig. 5.

This time the constructors were aware of the variety of solutions and even started calculating the possibilities. Unlike the previous situation when many of them thought that the right solution would be to guess the original construction this time they were proud to show what we agreed to call "counter examples" of the claim that the description is nonambiguous. To facilitate the checking they would use different colors for the consecutive steps in the description. When the teacher drew on the board the original construction the author of the description exclaimed: I don't believe I have written this.

The next task for all was to improve the descriptions so as to eliminate the ambiguity. In most of the cases the descriptions were much more precise:

Yavor - Build a row of 4 cubes. Put two cubes on the left side of the last one. Put 3 additional cubes above the leftmost cube. Put two more cubes on the right of the topmost cube.

Evgenia and Veronika: A row of 4 cubes. When looking from above - a row of 2 cubes is stuck to the left side of the forth cube. On top of the cube not touching the row a column of 3 cubes is built. Next to the topmost cube two cubes have been stuck towards the row of 4 cubes.

Nikola: Let us look the board from above and denote the 4 directions East, West, North, and South. There is a 4-cube row from West to East. The fourth cube is the one most to eastwards, next to the northern side of the 4th cube a row of 2 cubes is glued spreading to the North. The second cube is the one most to the North. On the top of it there are 3 cubes one over the other. On the southern side of the topmost cube of this column 2 cubes are spread from North to South, the second cube being most to the Southwards.
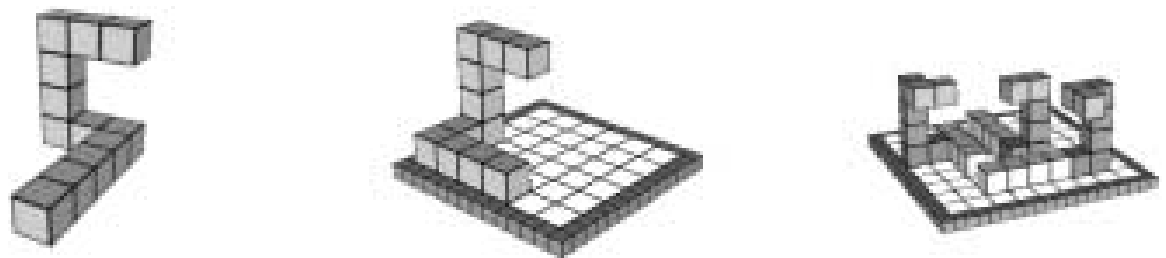

Fig. 5. Constructions based on a classmate's description of a figure. 
Although the ambiguity has been reduced this time there was a redundancy in most of the descriptions - thus the next task was to delete what was not necessary. Such interplay with the step-wise refinement of the descriptions would hopefully cultivate their skills for working with mathematical definitions so as to appreciate their compactness and precision. Furthermore, describing constructions and building after descriptions would prepare them better for programming in Logo.

Episode 4: Free-style constructions - session 1

The last task of the session involved a lot of imagination - the students were given the freedom of making their own constructions related to the real world. After that they had to describe them for their peers. At this point all kind of interesting creatures started appearing on the screens - robots, flowers, jumping dogs, fish in aquariums, shooting canons, etc., (Fig. 6).

Easy and pleasant to construct but so difficult to describe - especially when the construction had gaps ... How could we explain this? If it was in the plane, it is clear - we could use the notation of the chess board, but here? Then there came the insight: May I add one more line, something like a $3 D$ chess and use figures, Latin letters and Cyrillic letters? No sooner said than done (Fig. 7, left). This was a great generalization provided that they had no experience with coordinates other than the chess board and the cross words.

Other questions were related to the proper naming (a problem we often face with the Logo procedures): Can I say that this is a flower (a dog, a fish) and use a name for my construction? I will name the colored parts of my Ninja Turtle and this would help the builder to reconstruct it (Fig. 7, right) .... It made sense - they were talking to a peer. Thus the idea of organizing a contest in the style of Guess my object named so and so
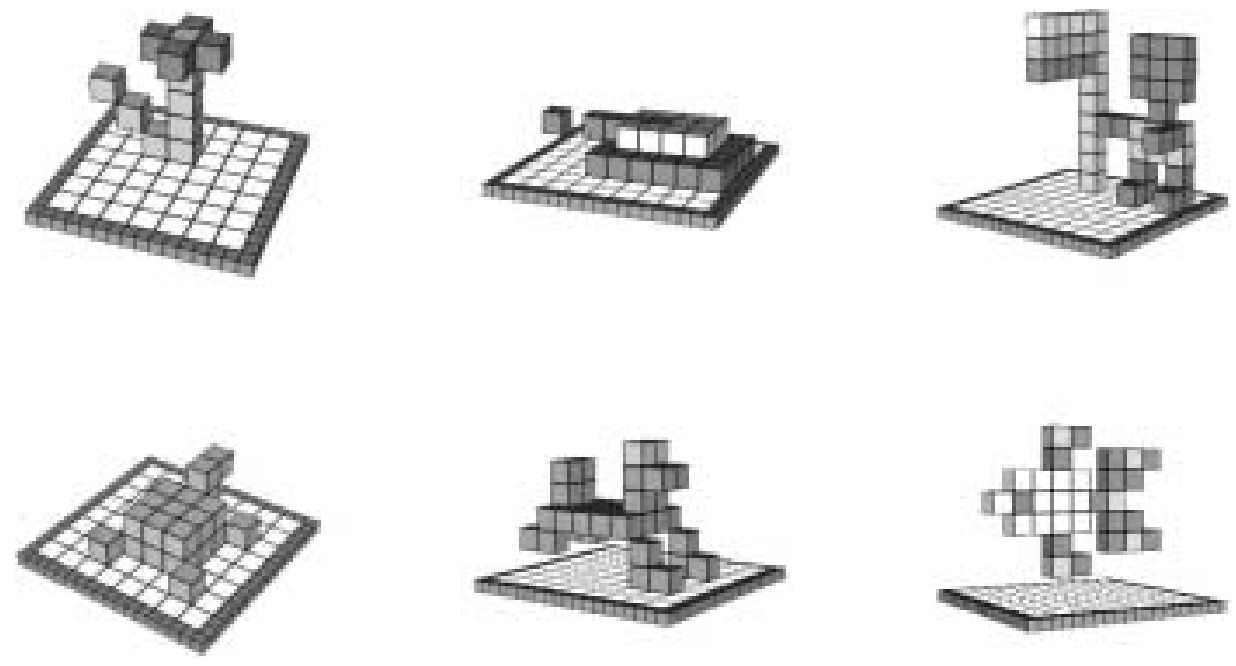

Fig. 6. Constructions in a free style. 

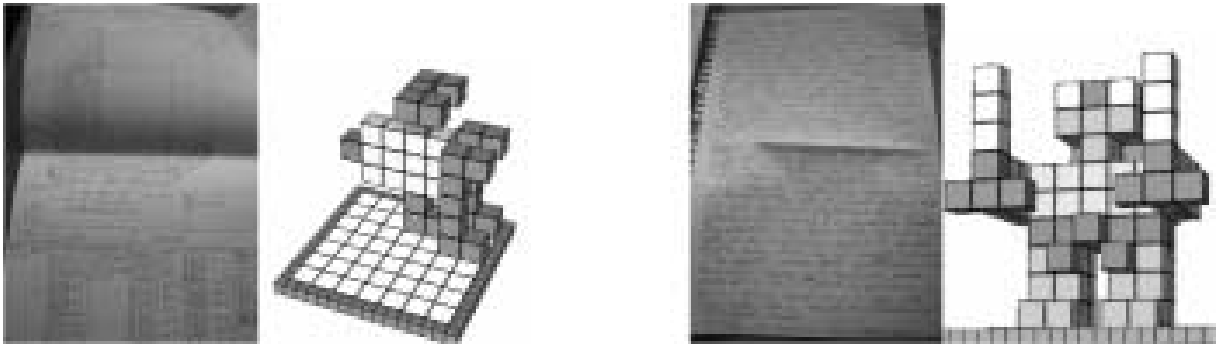

Fig. 7. Constructions in a free style with their descriptions.
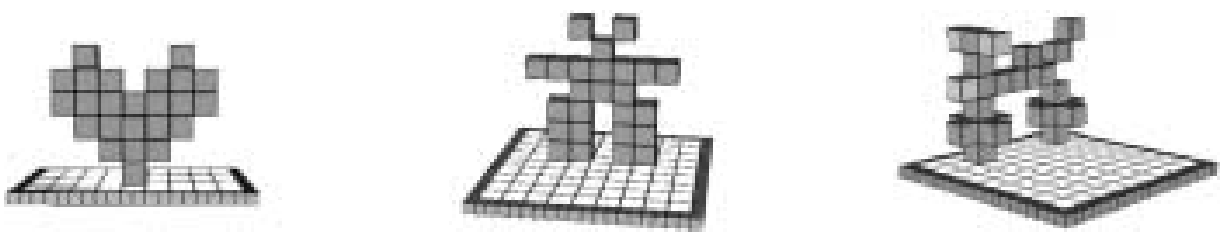

Fig. 8. Twenty-five cube constructions.
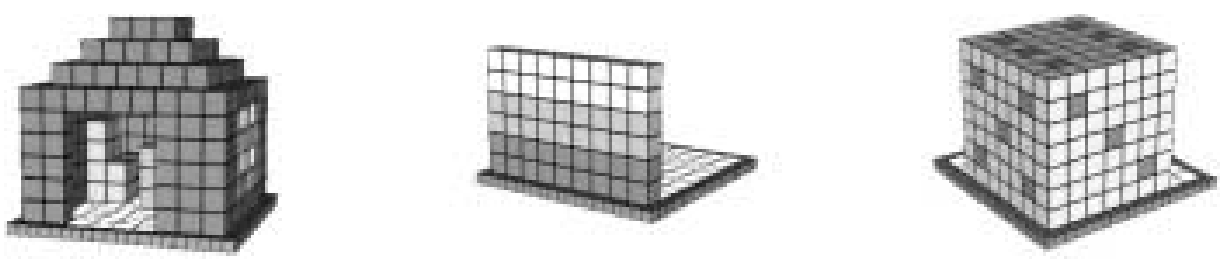

Fig. 9. Free style constructions - second session.

was born - the criteria would be to evaluate both the esthetics of the construction and the correctness of the description.

Episode 5: Constructing in a free-style or under constraints?

The next task was for the students to create and then describe a composition under the limitation of exactly 25 cubes. Even within such a constraint some of the constructions were imaginative and rather complex (Fig. 8).

It was interesting to observe that when left to work in a free style this time (unlike the previous session) some students would choose simpler constructions so as to facilitate the process of describing them. As seen in Fig. 9 the constructions included not only architectural pearls but objects relatively easier to describe.

Four descriptions were chosen by random and written on the board to be materialized - this time most of the figures coincided with the original but we still discussed with the students if this was a matter of chance or of the qualities of the description.

Naming the compositions with reference to real world objects helped to a great extent. Figs. 10 and 11 show the original constructions named correspondingly My dog and Trojan horse and some of their materialized descriptions. In the case of the Trojan horse 

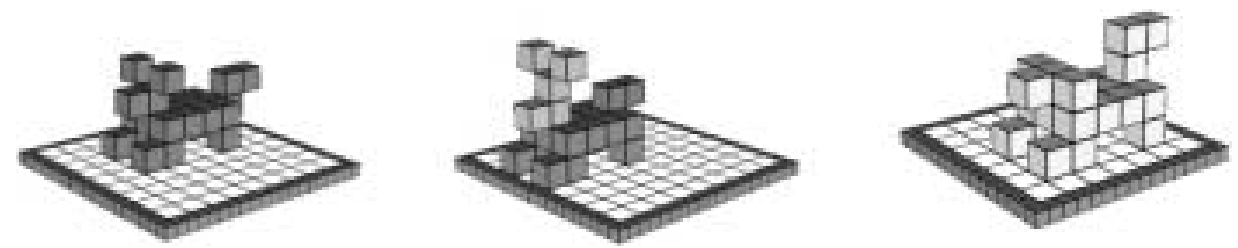

Fig. 10. The original dog and its variations according to the description.
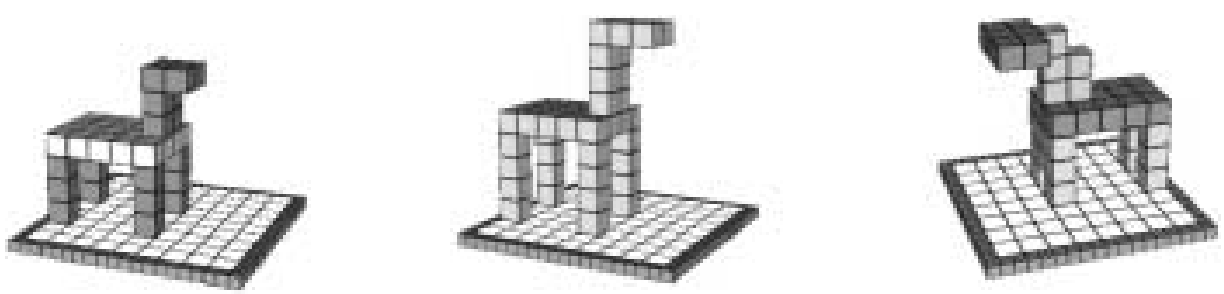

Fig. 11. The Trojan horse and some variations.

it was interesting for us to observe that some students decided not to follow strictly the description although it was quite clear and included information about the surface, the volume and the number of cubes: How could the legs be only 3-cube tall, why is the neck so short - it wouldn't look like a real Trojan horse?.. It was obvious that when the artist in you prevails you do not follow instructions ....

To work within different types of constrains - a fixed number of cubes and one's own endeavor to produce a non-ambiguous definition of a construction, turned out to be very interesting for the kids and for the teachers alike. The endeavor to produce not only an interesting construction but to make sure that their peers would reproduce it made many of the kids work hard at home. Next session they came with new descriptions, typed on a nice sheet of paper with a drawing, or a picture of their compositions attached on a separate sheet.

Episode 6: Developing a Logo-like vocabulary for describing cubics

When working with relatively big groups of students it was difficult for us to follow and debug the refinement-of-descriptions process for each individual. Therefore we were curious to experience this process in the style of a case study. Below is the dialog of a 10-year old girl (E) working with the third author $(\mathrm{P})$ in a face-to-face mode:

P: Please describe the constructions in Fig. 12.

$\mathrm{E}$ : (a) is 5 cubes one over another. (b) is 5 cubes in a row and another row above them. (c) is 4 cubes and 2 more cubes over the last one. (d) is . . huh ... I cannot say, but (e) is zigzag and ( $f$ ) is ... (as an orchestra conductor she 'draws' with hands in the air the shape of the figure)

P: Imagine you are in a cube and describe how you would go through all cubes. You can turn left or right, up or down if needed. Start with figure (c).

E: Step, step, step, step, turn up, step, step. 

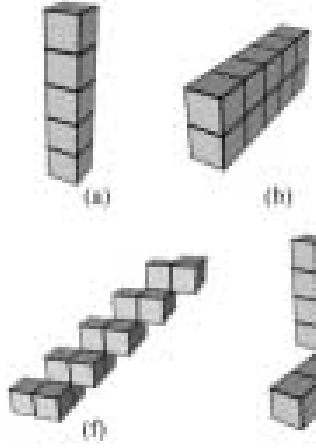

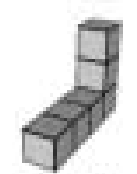

(6)

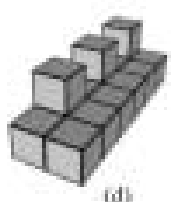

id

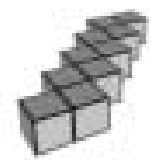

(e)
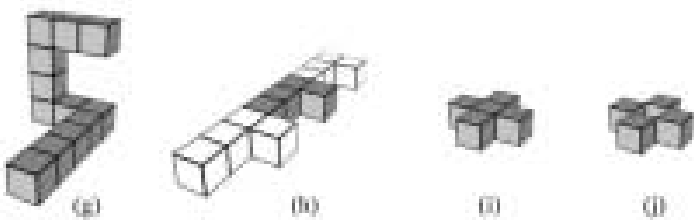

(i)

(i)

Fig. 12. A set of constructions to be described.

P: Now try figure (e).

E: Right, step, left, step, right, step, left, step, and so on.

P: And now try (f).

E: Step, step, left, step, turn up... Huh... I cannot do it.

P: OK, then. Try an easier figure. Try (g).

$\mathrm{E}$ : I'll start from the top-right cube. (She starts quickly) step, step, step, down, step, step, step . . huh . . . huh (here she tilts her head trying to figure out directions in an upside-down position) ... huh ... (continues very slowly) ... down, step, . . step ... left .... Is it left? (looks for a hint).

P: You see, you can describe the figures in this way, but what does make it still hard?

E: It's the turning (and she again tilts her head trying to express the feeling of disorientation with hands pointing left and right).

P: I see. Try to describe without turning. When you say 'left' it is as if you step to the left without turning. Try now (g) starting from the front cube.

E: Step, step, step, step, step, left, left, up, up, up, right, right ... (she smiles after describing the figure without pauses for thinking).

P: Go back to figure (f).

E: I will start from the .... (She thinks how to express the step towards us) ... nearer, left, down, (then continues quickly) nearer, left, down, nearer, left, down ... It is easy. (She even does not continue to describe the figure till the end, after realizing she got the pattern right).

P: And now try (h).

E: (waiting for a second thinking how to describe colors) The first one is white, then white (looking for another word for 'step') ... forward, white forward, white right, left, gray forward, gray forward....

P: Do you need to say 'white' and 'gray' for each cube?

E: (replaying silently figure (h) again) No, only when the color changes.

P: Let's now do figure (i).

E: Forward, right, left, left, right, forward.

P: Oh-key ... and now the last figure. 
E: (Facing a new challenge with the gaps in the structure) cube, step forward without cube (secretly looking to see any approval or rejection of her innovation .... and then continues boldly), step right with cube, step left without cube, step left with cube, step right with cube, forward with a cube.

P: Great! Now you see that it is easy to describe all figures once you have a suitable way for describing.

E: Yes, really (and she runs in her room to play a game of her own).

\section{Conclusions}

Feeling comfortable when expressing ideas doesn't come naturally. Learning a formal language (be it Logo or mathematics) is in many ways like learning a natural language - new vocabulary, syntax, semantics. Both types of languages require a lot of practice to make perfect but the formal languages lack ambiguity and vagueness.

At Eurologo 2005 a couple of very interesting educational issues were raised: How do we best help children to learn the new skill of writing algorithms? (Ó Dúill, 2005). How to teach students to explain their programs to others so that they understand the program? (Futschek, 2005). We explored these issues with the idea that writing descriptions/algorithms and executing them are important skills, essential for work in a computer environment and a good ground for the next stage of using Logo as a language.

The episodes with the students during DALEST experimental activities described above suggest that the language is playing significant role in the learning experiences of the students. Articulating their own ideas, developing concepts collaboratively with others, moving between everyday and mathematical terms, between procedural and declarative style, exploring the boundaries of understanding, were all phenomena we enjoyed observing. The descriptions the students wrote have not been fully analyzed yet - further analysis is needed to identify relevant categories and their relations to each other. Still the descriptions could be grouped according to some basic features: labeling the cubes; taking into account the initial conditions (number of cubes, size); using metaphors, mathematical objects, similarity to letters, projections; taking into account the symmetry and the repetition of elements; using relative movement; using coordinates.

The main satisfaction for us was that the students experienced the whole process of generating a good definition: becoming aware of the ambiguity, producing counterexamples, reducing the ambiguity, reducing the redundancy. In many situations their examples could be a good reference point to the specifics of the mathematical definitions. At the same time many of their observations regarding the cube structures such as symmetry, modularity, repetition, etc. introduced in a natural way the use of terms and phrases typical for the programming jargon. Such terms as repeat, repeat-until, forward, back left, draw a cube prepared the ground for introducing Logo (even in its 3D version) in a natural way. When describing the cubic structures the students were working topdown (from a general description to smaller and smaller details) or bottom-up (developing progressively more complex structures starting from components of the structure 
being described). Hopefully, at a later stage students would appreciate that techniques that were good for describing cubical structure are good for structured programming, as well. The refinement process itself was very much in the style of debugging a program rather than starting from scratch. We noticed that although the declarative descriptions prevailed there were also procedural ones or such in a mixed style. Just as in Logo the turtle drawing could be represented procedurally and declaratively (Blaho et al., 1994). So which style is more natural? When we asked a university student in mathematics what type of a description he would use for the cubic consturctions, declarative or procedural, he answered:

That would depend on to whom I'm talking: If I am speaking to a carpenter, it would be procedual - how to build it out of wood. If I am speaking to a mathematician, it would be procedual - how to build it out of elementary functions. To a sculptor, declarative. To most people, devlarative referring to common objects such as animals.

This was a perfect answer to our endeavor - to teach kids how to reach the right level of formalization depending on the context, the level between Gödel and Goethe.

\section{Instead of P.S.}

While staying in line for ordering some lunch at the institute canteen the day before submitting our paper, we were deeply involved in a philosophical conversation about the right level of language precision in a given context. When the turn of the third author arrived he uttered laconically: "A barbeque, please". The cook smiled and answered: Sorry, Sir, it is too heavy for me to fetch and carry ...

\section{Acknowledgments}

The work on this paper has been supported by the DALEST project co-funded by the European Union, under MINERVA action.

\section{References}

Blaho, A., I. Kalas, M. Matusova (1994). Symbolic Computations and Logo, Bratislava.

Boytchev, P. (2007). Cubix Editor, http: / /www. elica.net/site/download/dalest/ce.html

Boytchev, P.(2007). Elica, http: / /www. elica.net

Boytchev, P. (2007). Logo Tree Project,

http: / /www.elica.net/download/papers/LogoTreeProject.pdf

Boytchev P., T. Chehlarova, E. Sendova (2007). Enhancing spatial imagination of young students by activities in $3 D$ Elica applications. Proc. of the 36th Spring Conference of the Union of Bulgarian Mathematicians, Varna, Bulgaria, pp. 109-119.

Bruner, J. (1990). Acts of Meaning, Harvard University Press.

Christou, C. et al. (2007). Developing student spatial ability with 3D applications. Submitted to 5th Conference of the European Society for Research in Mathematics Education. Larnaca, Cyprus. 
DALEST Project, http: / /www. ucy.ac.cy/dalest/

Dicheva, D. et al. (1997). School informatics in Logo style: a textbook facing the new challenges of the Bulgarian informatics curriculum. In M. Turcsanyi-Szabo (Ed.), Learning and Exploring with Logo, Proceedings of the Sixth European Logo Conference Eurologo'97, Budapest, Hungary, 20-23 August, pp. 234-239.

Feynman, R., R. Leighton, M. Sands (1971). The Feynman Lectures on Physics, Vol. 1, Addison Wesley.

Filimonov, R., B. Sendov (1989). Drawing Logo closer to the curriculum. In G. Schuyten \& M. Valcke (Eds.), Proceedings of the Second European Logo Conference, Gent, Belgium, pp. 363-373.

Futschek, G. (2005). Explaining and understanding LOFO programs, a discipline of learning computer programming. In G. Gregorczyk et al. (Eds.), Proceedings, EUROLOGO'2005, pp. 327-333.

Kent, P., R. Noss (2002). The mathematical components of engineering expertise: the relationship between doing and understanding mathematics. I.E.E. Second Annual Symposium on Engineering Education, London, http: / / www.ioe.ac.uk/rnoss/MCEE/Kent-Noss-EE2002-preprint.pdf>

Khait, A. (2003). Goal orientation in mathematics education, International Journal of Mathematical Education in Science and Technology, 34(6), 847-858.

Khait, A. (2005). The definition of mathematics: philosophical and pedagogical aspects. Science \& Education, 14(2), 137-159.

Noss, R. (1993). The Politics of Logo. In P. Georgiadis, G. Gyftodimos, Y. Kotsanis, C. Kynigos (Eds.), LogoLike Learning Environments: Reflection\&Prospects, Proceedings of the Fourth European Logo Conference, Athens, Greece.

Nikolov, R., E. Sendova (1991). Informatics for all school ages. In E. Calabrese (Ed.), Proceedings of the Third European Logo Conference, Parma, Italy, pp. 83-96.

Ó Dúill, M. (2005). 2 intelligences: a bricolage. In G. Gregorczyk et al. (Eds.), Proceedings, EUROLOGO’2005, pp. 113-122.

Papert, S. (1980). Mindstorms. The Harverster Press.

Sendov, B., D. Dicheva (1988). A mathematical laboratory Logo style. In F. Lovis and E.D. Tagg (Eds.), Computers in Education, Proceedings of the IFIP TC3 European Conference on Computers in Education (ECCE'88). Lausanne, North Holland.

Sendov, B., E. Sendova (1993). Learning to speak mathematically and speaking mathematically to learn in the Logo-based environment "Geomland”. In P. Georgiadis, G. Gyftodimos, Y. Kotsanis, C. Kynigos (Eds.), Logo-Like Learning Environments: Reflection\&Prospects, Proceedings of the Fourth European Logo Conference, Athens, Greece, pp. 281-287.

Sendov, B., E. Sendova (1995). East or west - GEOMLAND is BEST, or does the answer depend on the angle? In A.A. diSessa, C. Hoyles, R. Noss (Eds.), Computers and Exploratory Learning. NATO ASI Series, Series F; Computer and Systems Sciences, Vol. 146, Berlin, Springer-Verlag, pp. 59-79.

Sendova, E. (1992). Enhancing the scientist into the pupil: a computer environment supporting discoveries in the classroom. In R. Aiken (Ed.), Education and Society, Information Processing 92, vol. 2, Elsevier Science Publishers B.V. (North-Holland), pp. 174-180.

Sendova, E. (1998). Identifying computer environments and educational strategies to support creativity and exploratory learning. In G. Davies (Ed.), Teleteaching'98 Distance Learning, Training and Education, Proceedings of the XV IFIP World Computer Congress.

Truss, J. (1999). Discrete Mathematics for Computer Scientists. 2nd ed, Addison-Wesley.

Vinner, S. (1991). The role of definitions in teaching and learning mathematics. In D. Tall (Ed.), Advanced Mathematical Thinking. Kluwer Academic Publishers, pp. 65-81.

Vygotski, L.S. (1934). Language and Thought. Gosizdat, Moscow (translation from Psycholinguistics, Holt, Rinechart and Winston, NY, 1961, p. 509). 
E. Sendova is a senior researcher at the Institute of Mathematics and Informatics, Bulgarian Academy of Sciences. Her interests are in using informatics and ICT for teaching mathematics, languages, music, science and arts. She has been working on developing Logo microworlds and models for integrating learning and creative processes. For more than ten years Jenny has been involved in working with high school students highly motivated in studying mathematics and science.

Toni Chehlarova is assistant professor at Faculty of Mathematics and Informatics, Plovdiv University. She is involved in mathematics education by teaching students from 1st to 12th grade and training teachers-to-be. She delivers courses in mathematical didactics, methods in teaching mathematics, methodology of the pedagogical research, methods for problem solving, implementing ICT in education.

Pavel Boytchev is an associated professor at Faculty of Mathematics and Informatics, Sofia University. Author of Elica and a developer of educational software. Designs and teaches Logo-based courses "Computer Graphics" and "System and Environments for Electronic Education". 


\section{Žodžiai - sidabru austi, pelès spustelèjimai - auksu žvilgantys ...} (arba kaip pagerinti jaunesniuju mokiniu kalbos formalizavimo lygi, panaudojant Logo ervinius mikropasaulius)

\section{Evgenia SENDOVA, Toni CHEHLAROVA, Pavel BOYTCHEV}

Kaip vaikai mokomi išreikšti ir perduoti savo mintis formaliais arba neformaliais būdais? Kokia kalba jiems reikalinga konkrečiame kontekste? Šiame straipsnyje bandoma atsakyti šiuos klausimus tiriant Bulgarijos penktokus. Tyrimas patvirtino, kad kalba atlieka svarbu vaidmenị. Penktokai, sudarydami ir apibūdindami erdvines struktūras, aiškiai reiškia mintis, plètoja bendrą supratimą bendradarbiaudami su kitais, tapatindami matematinius terminus su kasdienybe, tyrinėdami savo supratimo ribas. Toks mokymas turètu padèti panaudoti mokinių turimas žinias apie matematinius terminus ir padèti jiems pasirengti programoms rašyti, derinti ir testuoti. 